\title{
TREE SWAY PERIOD-A POSSIBLE NEW PARAMETER FOR CROWN CLASSIFICATION AND STAND COMPETITION ${ }^{1}$
}

\author{
BY MARTIN J. SUGDEN ${ }^{2}$
}

Martin James Sugden was born in Galt, Ontario, in December 1933. He was granted his B.Sc.F. in 1958 at the University of Toronto and studied at the Ontario College of Education in Toronto in 1959. Mr. Sugden's undergraduate thesis on Buoyed cable logging was published in the Woodland Section of the C.P.P.A. At present he is teaching mathematics at Lakefield District High School and is taking summer courses leading to a specialist's certificate in mathematics.

\section{ABSTRACT}

The natural sway periods of red pine (Pinus resinosa Ait.) and some white pine (Pinus strobus L.) trees were measured with a stop watch in four plantations and one native stand. This new parameter showed fair correlation with the ratio diameter/height; deviations therefrom were thought to be due largely to the variable mass and height of the crown. The crowns were pruned from six large red pines and the sway periods of their pruned boles were observed. "Crown moment" was postulated as a more all-inclusive index than either crown density or crown class alone. Other possible factors affecting tree sway period were discussed, although the relative importance of each remains to be investigated. Sway period frequency curves for each stand suggested that the mean sway period of a stand increases with age and with increasing competition.

\section{INTRODUCTION}

The long periods of time required to mature a tree crop or even to resolve a problem in forest research have tended perhaps to blind investigators in the past from experimenting with any parameter using time measured not in years, but in seconds. Perhaps the unrhythmic sway of trees caused by fitful winds has served to discourage any idea of sway measurements in forestry for as long as accurate time-pieces have existed. Nevertheless, in calm air, a tree like any beam fixed at one end may be made to vibrate with a constant period related to the form and distribution of mass along its length. In the research literature, however, the writer has found but one reference which leads directly to the subject of this paper, tree sway period.

R. Geiger (1950) discussed briefly the effect of successive gusts of wind upon a tree in rhythm with its natural period of oscillation. He noted that the danger of breakage or uprooting is much increased during such resonant gusts. He also pointed out that the mass distribution in a tree determines the period of its movement to and fro once the impulse has been imparted by the wind, and that wind damage may often result not from wind pressure alone but from this resonance phenomenon.

\footnotetext{
${ }^{1}$ Material for this paper was gathered as a personal spare time project while working on the Petawawa Forest Experiment Station, Department of Forestry, in the summer of 1959. The author gratefully acknowledges the provision of three of the photographs, instruments for use after hours, current diameter and height records of P.S.P. 146, and permission to prune the six red pines.

${ }^{2}$ Box 232, Lakefield, Ontario.
} 
It would seem that the period of vibration of a tree measured in seconds is as fundamental a biometric property of the tree as is its height and diameter. Perhaps tree sway period is the truly fundamental property when one realizes that it is an expression of the infinite number of diameters measured at increasing heights up the bole. For a weightless beam of mass $\mathrm{M}$ concentrated upon it at height $\mathrm{L}$, the period $\mathrm{T}$ of the beam is expressed by the formula

$$
\mathrm{T}=\mathrm{kML}^{\mathrm{s}}
$$

where $\mathrm{k}$ is a complex constant of proportionality. The writer has found this formula to apply closely with a thin bamboo rod swaying with the concentrated mass of a metal object fixed successively at points along its length. The tree, of course, is not a weightless beam, but has its mass including branches distributed along its length. The formula for tree sway period requires use of the calculus, and will not be treated in this paper. In general, however, tree sway period $\mathbf{T}$ (the length of time in seconds for one vibration) decreases as diameter increases, height and branch weight remaining constant, while $\mathrm{T}$ increases as height increases, all else remaining constant. (It should be remembered that period $T$ is the reciprocal of the frequency of vibration $f$.)

Reference to the work of Metzger as outlined by Büsgen and Münch is also illuminating. Metzger's well supported theory assumes that a tree increases its diameter in response to the demands of wind, snow and ice upon the mechanical strength of the tree bole. However, crown, roots, and fruit have priority in competing for materials, and the bole must economize by growing new wood only where it is needed. If any beam fixed at the base is to present along its entire length an equal resistance to a bending force at the top, such a beam requires at any length from the top a diameter of wood whose third power is proportional to that length. Such a beam is called, in engineering parlance, a beam of uniform resistance, and it takes the shape of a paraboloid. The greater part of tree boles are also paraboloid; the straining of the stem by wind is seen as the stimulus which promotes this mathematical deposition of wood wherever it is required to provide equal strength along the bole. However, Metzger skirted the whole subject of tree sway period, and no direct application of his work will be made in this paper.

The writer was curious to learn what periods of vibration actually existed both in individual trees and in pure and mixed stands, and to discover any pattern in the variation of sway periods within a stand, as well as the possible relations of tree sway period with diameter and height for given trees.

In the summer of 1959 the writer began these investigations mainly upon plantations of red pine as a spare time project while employed at the Petawawa Forest Experiment Station.

\section{Method of Measurement}

For reasons mentioned at the beginning of the introduction, it was decided that the vagaries of wind should play no part in the observations. The wind factor was eliminated by waiting until a time of day when the forest was hushed completely. Many timings were made therefore either in the early morning or evening. 
It was found that pines as large as 15 inches Dbh could be made to sway perceptibly by the rhythmic push-and-pull application of manual force at breast height. For such large trees, the rate of push and pull must be varied until upon looking up the tree boughs are seen to move slightly in resonant motion. The force is then withdrawn, and a stop-watch measuring tenths of seconds is started and stopped embracing always a period of five counted vibrations of the tree top.

Four separate timings of five vibrations each, one in each cardinal direction, were recorded and later averaged. (Often a tree would consistently give a slightly greater sway period in one direction than another, probably owing to an elliptical bole.) The average time for five vibrations was divided to obtain the tree sway period, $T$, for one vibration (to and fro).

In the dense stand, some of the trees influenced one another's sway period due to touching or even interlocking branches. Although a note was made of the more serious cases, their sway period was included in the data as contributing in part to the natural sway pattern for the whole stand.

The few wholly dead trees still standing were ignored, however; their period was very much shorter than living trees, probably due to their dry wood and the lack of branch mass.

The branches of most trees were observed to vibrate at the same period as the bole. An almost negligible proportion of live trees would not vibrate enough times for adequate measurement, because their motion was damped rapidly to zero amplitude. It was noted that the branches of these nonrhythmic trees appeared to vibrate with a different period than their boles; that is, the branch sway may have damped the bole sway. This phenomenon might be ascribed to the rapid adjustment of branch growth to radically different light conditions (such as caused by a dying neighbour); at the time of sway measurement the bole growth may not have been keeping pace with branch growth. Another possible explanation may be an injury incurred by part of the tree.

All diameters were read from a diameter tape to the nearest hundredth inch, and all heights were read from a Haga altimeter to the nearest half foot.

\section{Plots Studied}

The most significant part of the study revolves around two very different permanent sample plot plantations of red pine at the Petawawa Forest Experiment Station. Both plots, each about $3 / 4$ acre, were located less than 200 feet apart on rolling, well-drained sandy soil, and both had been planted in 1926 , seedlings about the usual 5 feet apart. However, PSP 197 has been left unthinned to the present (Fig. la) whereas in PSP 196 the alternate rows had been removed including the alternate trees in the remaining rows (Fig. 1b). Although PSP 197 contained over 400 trees, only the first 175 trees' diameters, heights and sway periods were tallied. In PSP 196, 98 trees were similarly observed which comprised the whole sample plot less a few trees rejected from the study.

The sway periods, diameters and heights of 210 trees were also recorded PSP 146 (Fig. 1c), a native mixed wood of red and white pine about 70 years old. This plot was intended to be cleared for an expanding tree

Figures 1a-d are on page 349 and 350 
nursery, and so the plot also furnished observations on the sway periods of six completely pruned red pine boles, one of which is shown in Fig. 1d. The site of this plot was similar to the first two described.

Two other plantations ( $5^{\prime} \times 5^{\prime}$ spacing) were studied in September of 1960. The one, owned by Mr. G. Tedford, is located beside Highway 28 just north of Young's Point, Ontario. It was planted in 1938 to alternate rows of red and white pine; about two-thirds of the white pine have since died and been removed. Of the remaining trees, 213 were tallied for sway period, and about 40 of these trees were also measured for diameter and height. The other plantation was about 10 year old pure red pine, in high, rolling, wind-swept pasture just south of the Peterborough County Forest, and will be referred to hereafter as the Havelock Plantation. The canopy had not yet closed over. The sway periods of 130 of these young trees were recorded.

\section{GRAPHical ANALYSIS}

The most suitable correlate of sway period $T$ was sought for graphic expression. The graph of sway period plotted over diameter ( $T / D$, Fig. 2 ) showed only a somewhat diffuse correlation. Since the sway period clearly is affected to some extent by the degree of stockiness of the bole, the simplest expression representing the proportions of the bole was found in the ratio of diameter/height, $(\mathrm{D} / \mathrm{H})$. The $\mathrm{D} / \mathrm{H}$ ratio was calculated for each tree from its diameter in inches and its height in feet. Trees with greater

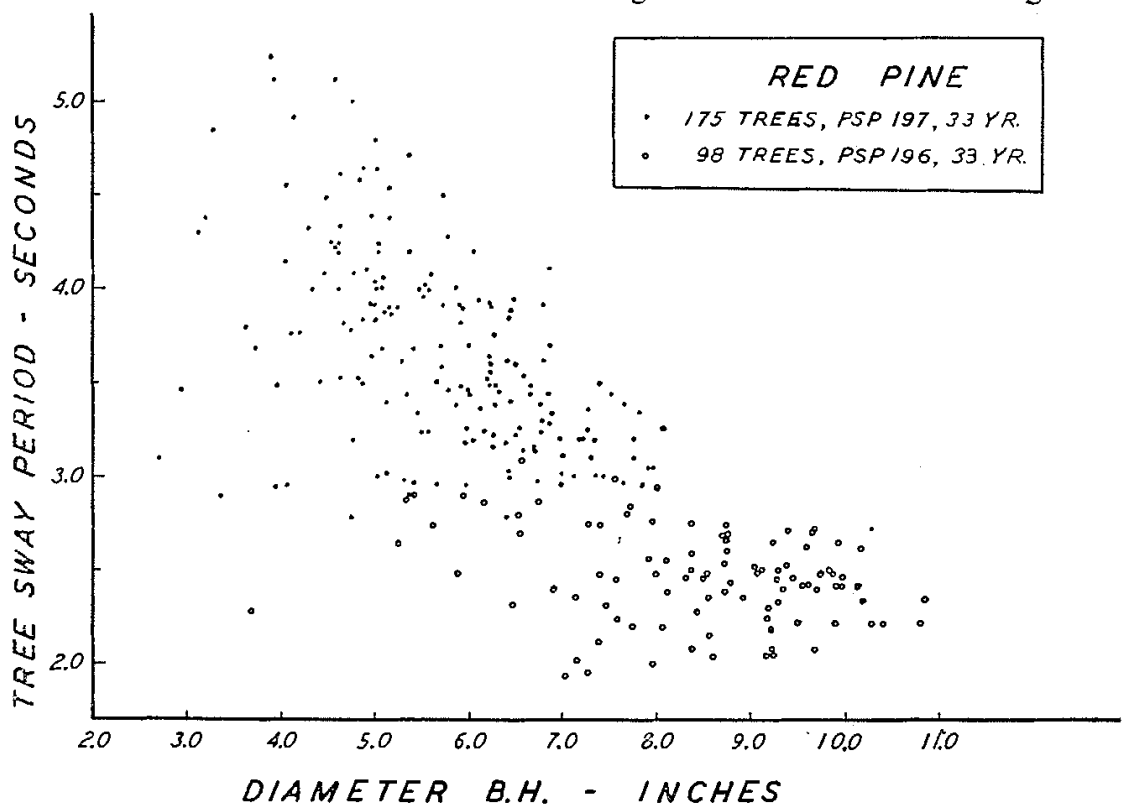

FIGURE 2. Correlation of sway period $T$ with diameter $D$ appears diffuse when compared with the sharper correlation of $\mathrm{T}$ in Fig. 3 .

$$
\overline{\mathrm{D} / \mathrm{H}}
$$


$\mathrm{D} / \mathrm{H}$ ratios are stockier in form. Naturally, the stockier tree will tend to vibrate with a shorter period.

The writer has been tempted to combine the 273 observations from both plots PSP 197 and PSP 196 in a single graph of $\frac{\mathrm{T}}{\mathrm{D} / \mathrm{H}}$, (Fig. 3), feeling justification from the exact same age of each plot, and the fact that the points from each plot appear to form a continuous curve. Because of the different ages and sites of the Young's Point plantation and the Havelock plantation, the data from these stands were not included in Fig. 3.

The correlation $\frac{T}{\mathrm{D} / \mathrm{H}}$ appears considerably sharper than that for $\mathrm{T} / \mathrm{D}$. A balanced curve for the former graph was computed and inserted as shown.

The graph of $\frac{\mathrm{T}}{\mathrm{D} / \mathrm{H}}$ for the 210 trees in PSP 146 showed a scattering of points with little or no trend; no graph is shown for this plot.

\section{Pruned bole Curve}

It was thought that a few trees selected for various $\mathrm{D} / \mathrm{H}$ ratios and then pruned to the top would yield a $\frac{T}{\mathrm{D} / \mathrm{H}}$ curve of basic physical simplicity

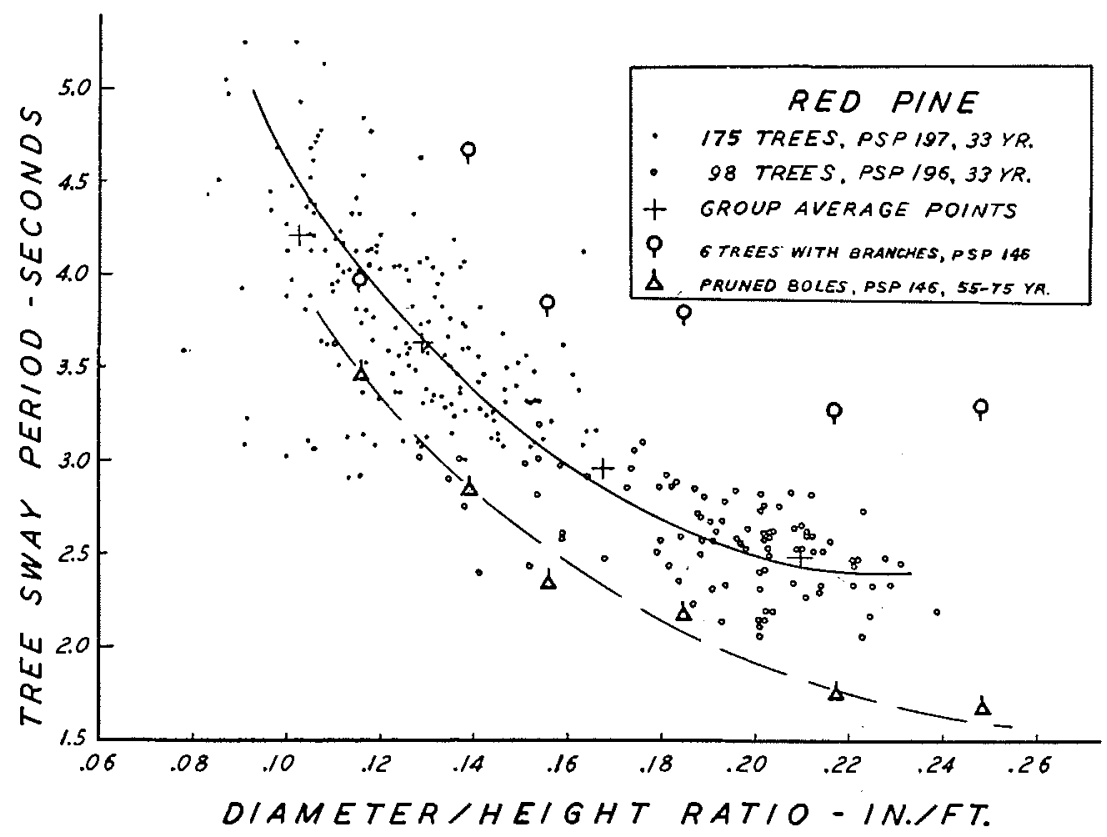

FIGURE 3. The solid curve shown is balanced for the correlation $T$. The broken curve

$$
\mathrm{D} / \mathrm{H}
$$

is freehand through the points representing the 6 pruned boles. 
bereft of the effects of branch mass and distribution. By this means one might isolate the proportion of tree sway period caused by the crown alone.

Accordingly, from the native stand PSP 146 nearby were selected six healthy trees with widely different $\mathrm{D} / \mathrm{H}$ ratios. Five of the trees were dominant or co-dominant, and the sixth, selected for its low $\mathrm{D} / \mathrm{H}$ ratio, was of the intermediate class. First, their natural tree sway periods (with branches) were recorded. Then all branches were pruned with a saw (Tarzan method) to within five feet of the top (Fig. 1d), and the bare boles timed for periodic sway. Data relevant to these six trees are shown in Table 1, while the ratios and sway periods are shown plotted in Fig. 3. A freehand curve was drawn through the pruned bole points.

TABLE 1

Data on the Six Red Pines in PSP 146 Providing Pruned Bole Curve

\begin{tabular}{rlcccccr}
\hline $\begin{array}{c}\text { Tree } \\
\text { No. }\end{array}$ & $\begin{array}{c}\text { Age } \\
\text { yr. }\end{array}$ & $\begin{array}{c}\text { Dbh } \\
\text { in. }\end{array}$ & $\begin{array}{c}\mathbf{H} \\
\text { ft. }\end{array}$ & D/H & $\begin{array}{c}\text { T } \\
\text { with } \\
\text { branches } \\
\text { sec. }\end{array}$ & $\begin{array}{c}\text { T } \\
\text { without } \\
\text { branches } \\
\text { sec. }\end{array}$ & $\begin{array}{c}\text { Weight of } \\
\text { branches } \\
\text { (living and } \\
\text { dead) Ib. }\end{array}$ \\
\hline 84 & 58 & 6.87 & 59 & .116 & 3.86 & 3.34 & 30 \\
89 & 73 & 10.28 & 74 & .139 & 4.56 & 2.76 & 170 \\
174 & 68 & 11.06 & 71 & .156 & 3.74 & 2.24 & 273 \\
118 & $68+$ & 13.84 & 75 & .185 & 3.68 & 2.06 & 390 \\
10 & $64+$ & 15.20 & 70 & .217 & 3.16 & 1.64 & 678 \\
212 & 73 & 16.92 & 68 & .249 & 3.18 & 1.54 & 1,061 \\
\hline
\end{tabular}

The weights of branches were accumulated for each tree with the aid of a pocket spring balance, but no use has been made of these figures. It is possible that the calculus could be used to verify the distribution and mass of these branches on the bole.

It is questionable whether the pruned bole curves for all stands of red pine would be located in the same position in Fig. 3. It was noted that the Young's Point trees (not plotted in Fig. 3 because of lesser age) in spite of their branch mass were located below even the pruned bole curve of PSP 146. Clearly, had it been possible to prune the Young's Point trees, they then would have fitted a curve still further beneath the bole curve of PSP 146. However, the Young's Point tree sway periods were observed late at night on the first of October at a temperature of $38^{\circ} \mathrm{F}$., a fact which may have caused some reduction in sway period. Indeed, records kept over winter on two cottonwoods in the leafless condition show slight decreases in sway period with relatively large decreases in below-freezing temperatures.

A general observation on Figure 4 reveals that with increasing age there is a gradual shift of the mode into the sway periods of larger duration.

\section{Discussion}

The position of the mode of each histogram cannot be related to age alone, for PSP 196 and 197 are of exact same age but radically different modes. Three basic assumptions may help to clarify the situation. 
1. The sway period of a red pine tree increases with age for most of its life. This is simply a re-statement of the general observation of Fig. 4. We also know that a young tree elongates tremendously at first, thus increasing the sway period, and at a later age as height growth ceases, the tree continues to increase in girth. Whether the tree's period then actually decreases slightly in old age remains to be investigated.

2. Open-grown even-aged red pines will have the same sway period. The truth of this assumption could be verified by studying the period/age relationship for a number of red pines growing sufficiently far apart in an

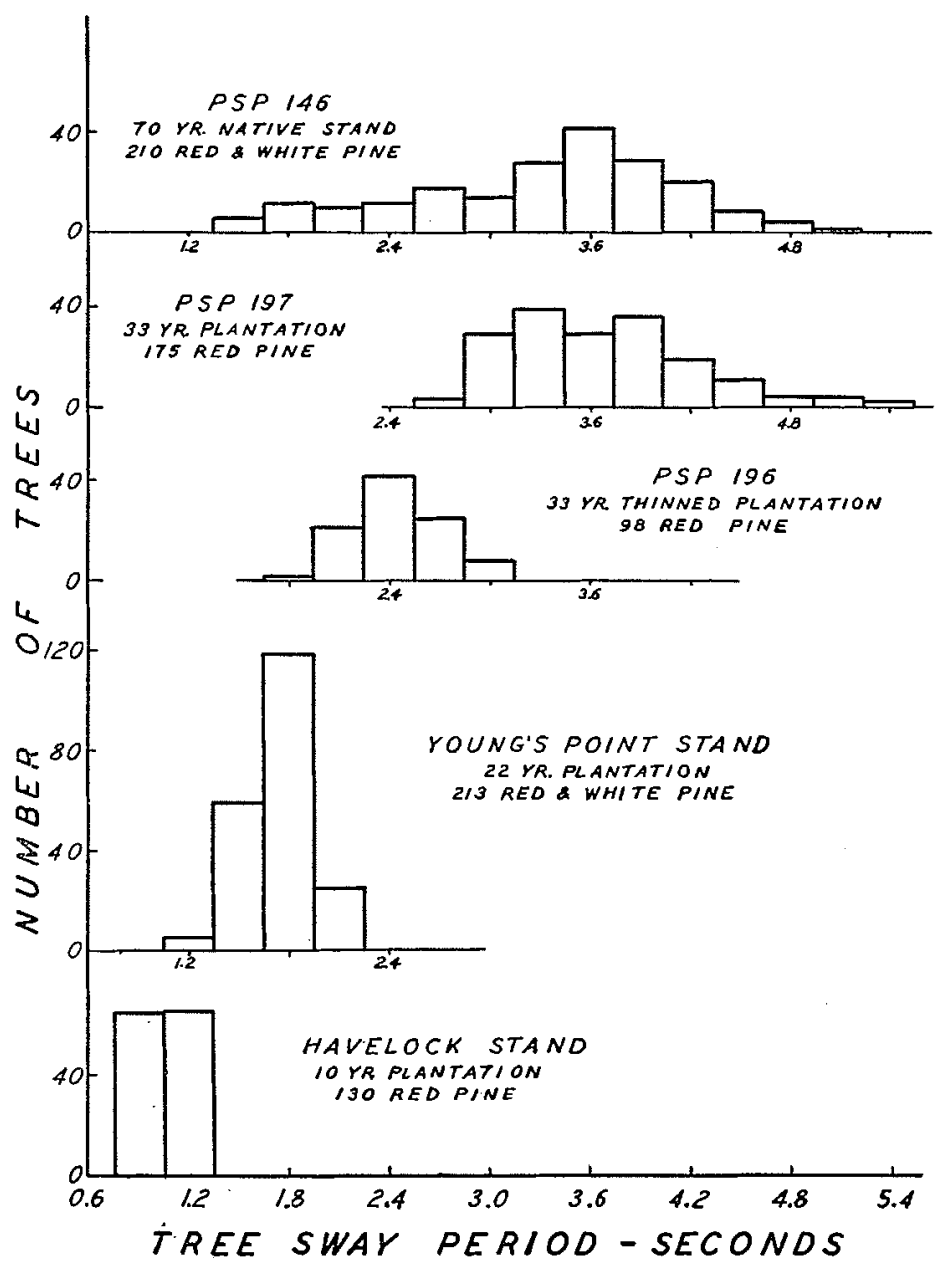

FIGURE 4. In this set of frequency histograms, note the gradual shift of the modes of the 4 plantations into the sway periods of longer duration with increasing age or competition. Note the dimodal tendency in highly competitive P.S.P. 197. 
open field as to be under no influence from their nearest neighbours. All trees would need also to suffer roughly the same wind velocity.

3. Stand competition serves to hasten a tree's progress into sway periods of greater duration. This assumption would explain the greater mean sway period of PSP 197 compared to PSP 196 of the same age in which alternate trees had been removed. (Compare Figs. la and lb). The greater competition in PSP 197 would serve to accentuate height growth at the expense of diameter growth thus contributing to a greater over-all sway period.

If the three assumptions are proved correct, then two factors may be held responsible for the increase of sway period: increasing age and increasing competition. Indeed, viewed in this light, sway period appears to be a near-perfect biometric index of these two conditions, stressful in the life of any organism.

There now remains a summary of the agencies through which age and competition actually work their changes in tree sway period. That is to say, the sway period of a tree may be seen to derive from at least three distinct major components:

\section{D/H ratio of the bole.}

2. Mass and distribution of the crown. The heavier the crown, or the higher its centre of mass, the greater will be the sway period. The above components have been discussed elsewhere.

3. Possible other component factors-wood structure, water content, pathological alteration, and temperature. In two pruned boles of identical age and $\mathrm{D} / \mathrm{H}$ ratio, it seems possible that different climate and soil may have conspired to alter their wood cell structure, their pattern and size of annual rings, or their form quotient so as to establish a definite difference in the sway period of each bole. In a single tree, moreover, the variable water content of a given tree, as graphically illustrated by Büsgen and Münch, likely seems capable of altering the sway period within a single season. If this is true, the large number of trees observed between the beginning of June and the middle of August, 1959, undoubtedly will have been affected. The age of a tree may therefore affect sway period through the agency of changing $\mathrm{D} / \mathrm{H}$ ratio with time, through the agency of changing mass and distribution of crown, and through the agency of the changing quality of the wood with the passing of time.

Pathological alteration of large areas of the wood of the bole would almost as certainly alter sway period as would structural alteration due to other factors. This factor could in large part be identified through the observation of crown health and the presence of conks, as well as by inspection of the wood with an increment borer.

The effect of temperature has been outlined elsewhere.

\section{Applications}

It is possible that sway period may provide a more quantitative means of describing crown class and crown density, if due allowance may be made for the complicating factors described above. From the sway period of the tree with its crown might be subtracted the average sway period for the 
pruned bole of a tree of similar age, diameter and height. The remainder obtained might be referred to as the crown moment for the individual tree, the term being reminiscent of the mass-distance product in a statics problem with a point mass concentrated at a certain distance along a weightless beam.

It was also thought that the new parameter, sway period, might prove useful as an improved expression for stand density. Spurr (1952) suggests that in order to comprehend the effect of density on growth, we must return to the biological basis of growth. One of the factors affecting growth is growing space, the inverse of competition. Sway period does seem directly related to the degree of competition. Spurr suggests that the ideal measure of density should be simple and objective, and sway period certainly fulfills those qualities. However, he adds that the measure of density should be largely unrelated to the character and age of the stand and the quality of the site. Sway period may be independent of site quality, but appears definitely related to age. Perhaps, then, it would be better to restrict sway period as a measure of biological competition after due allowance has been made for the age of the stand and other factors.

\section{CONCLUSION}

The above discussion has attempted to clarify the significance and possible uses of a new parameter, sway period, while outlining the pitfalls usually associated with generalizations in forest biology. The parameter appears to have raised more questions for further research than it has provided proven uses for so far. In practice, however, it is hoped that sway period may assist in explaining what happens in the process of stand decimation, and give a clearer view of the effect of thinnings on the development of residual trees.

\section{REFERENCES}

1. BUSGEN, $M$ and E. MUNCH, 1929. The Structure and Life of Forest Trees. Third Ed. Chapman and Hall, London. Pp. 166-8, and pp. 307-9.

2. GEIGER, R. 1950. The Climate Near the Ground. Harvard University Press. P. 302.

3. SPURR, S. H. 1952. Forest Inventory. Ronald Press, New York. Ch. 19. 